\title{
Recomendações na doação de leite materno aos bancos de leite humano frente à pandemia do COVID-19
}

\author{
Recommendations for donating breastmilk to human milk banks considering the COVID-19 \\ pandemic
}

Recomendaciones sobre la donación de leche materna a los bancos de leche humana frente a la pandemia de COVID-19

Vanessa Javera Castanheira Neia ORCID: https://orcid.org/0000-0003-2573-3457

Universidade Estadual de Maringá, Brasil E-mail: nutrivanjavera@hotmail.com

Christyna Beatriz Genovez Tavares ORCID: https://orcid.org/0000-0003-1671-5425

Universidade Estadual de Maringá, Brasil E-mail: cbgenovez@gmail.com

Isadora Boaventura Ponhozi ORCID: https://orcid.org/0000-0001-7230-161X

Universidade Estadual de Maringá, Brasil E-mail: isa.ponhozi@gmail.com Bruna Tiaki Tiyo

ORCID: https://orcid.org/0000-0002-8107-9536 Universidade de São Paulo, Brasil E-mail: brunatiyo@gmail.com

Luciana Pelissari Manin

ORCID: https://orcid.org/0000-0002-5429-5743 Universidade Estadual de Maringá, Brasil

E-mail: lucianapmanin@hotmail.com

Roberta da Silveira

ORCID: https://orcid.org/0000-0002-0037-4307 Universidade Estadual de Maringá, Brasil E-mail: dasilveira.roberta@gmail.com

Lucas Ulisses Rovigatti Chiavelli ORCID: https://orcid.org/0000-0002-4708-274X Universidade Estadual de Maringá, Brasil

E-mail: lucasulisses.uem@gmail.com

Fernando Hideki Fuyama

ORCID: https://orcid.org/0000-0003-0181-1318

Universidade Estadual de Maringá, Brasil E-mail: ra107467@uem.br Lorena Visentainer

ORCID: https://orcid.org/0000-0003-2706-3098 Lion Derm Concept, Brasil

E-mail: lovidermatologia@gmail.com

Oscar Oliveira Santos

ORCID: https://orcid.org/0000-0002-9631-8480

Universidade Estadual de Maringá, Brasil E-mail: oosjunior@uem.br

Jeane Eliete Laguila Visentainer ORCID: https://orcid.org/0000-0002-5815-7903

Universidade Estadual de Maringá, Brasil E-mail: jelvisentainer@gmail.com Jesui Vergilio Visentainer

ORCID: https://orcid.org/0000-0003-3412-897X

Universidade Estadual de Maringá, Brasil E-mail: jesuiv@gmail.com

\section{Resumo}

Objetivo: Discutir as recomendações de doação de leite materno aos Bancos de Leite Humano (BLH) frente à pandemia COVID-19. Metodologia: A pesquisa foi realizada envolvendo publicações sobre BLH, leite humano doado 
(LHD) e COVID-19 indexados nas bases de dados eletrônicas PubMed (US National Library of Medicine), Scientific Electronic Library Online Brasil (SciELO), Web of Science e Portal Capes. Os descritores que delimitaram a pesquisa foram: amamentação, aleitamento materno, BLH, LHD, leite humano, COVID-19, pandemia e Sars-CoV-2 em português e inglês. Resultados e discussão: Como o vírus da COVID-19 é transmitido por gotículas respiratórias e o vírus sobrevive por períodos variados em superfícies inanimadas, neste trabalho observamos as principais medidas de controle de transmissão do vírus pelo LHD durante todo o processo de coleta, processamento e distribuição do leite humano até os recém-nascidos das Unidades de Terapia Intensiva Neonatal (UTIN). É necessário controle de qualidade com alto rigor higiênico-sanitário do LHD como esterilização dos materiais que entrarem em contato com o leite materno, higienização do ambiente onde será realizada a ordenha, utilização de gorro e máscara, lavagem das mãos com água e sabão e eliminação dos primeiros jatos de leite ordenhado. Conclusão: As doadoras de leite humano ordenhado devem realizar uma triagem nos BLH para avaliação e orientações antes de iniciar a doação de leite humano, a fim de evitar a transmissão do vírus da COVID-19 durante todo o processo de coleta, processamento e distribuição do leite humano até os recém-nascidos das UTIN.

Palavras-chave: Amamentação; Leite humano; Bancos de leite humano; COVID-19; Recém-nascidos.

\begin{abstract}
Objective: Discuss the recommendations for donating breastmilk to Human Milk Banks (HMB) considering the COVID-19 pandemic. Methodology: The research was carried out involving publications on HMB, donated human milk (DHM) and COVID-19 indexed in the electronic databases PubMed (US National Library of Medicine), Scientific Electronic Library Online Brazil (SciELO), Web of Science and Portal Capes. The descriptors that delimited the research were: breastfeeding, maternal breastfeeding, HMB, DHM, human milk, COVID-19, pandemic and Sars-CoV-2, in Portuguese and English. Results and discussion: As the COVID-19 virus is transmitted by respiratory droplets and the it survives for varying periods on inanimate surfaces, in this work, we observe the main measures to control the virus transmission through the DHM during the entire process of collecting, processing and distributing the human milk to the newborns in the Neonatal Intensive Care Units (NeoICU). Quality control with high hygienic and sanitary rigor of the DHM is essential, such as sterilization of materials that come into contact with breastmilk, cleaning of the environment where milking will be carried out, use of cap and mask, hand-washing with soap and water, and disposal of the first jets of milked milk. Conclusion: Donors of milked human milk must perform a screening at the HMB for evaluation and guidance before starting the human milk donation, in order to avoid the transmission of the COVID-19 virus during the entire process of collecting, processing and distributing human milk to the newborns in the NeoICU.
\end{abstract}

Keywords: Breast-feeding; Human milk; Human milk banks; COVID-19; Newborns.

\title{
Resumen
}

Objetivo: Discutir las recomendaciones para la donación de leche materna a los Bancos de Leche Humana ante la pandemia de COVID-19. Metodología: La investigación se llevó a cabo con publicaciones sobre Bancos de Leche Humana, leche materna donada y COVID-19 indexadas en las bases de datos electrónicas de PubMed (US National Library of Medicine), Scientific Electronic Library Online Brasil (SciELO), Web of Science y Portal Capes. Las palabras clave que delimitaron la investigación fueron: amamantamiento, lactancia materna, banco de leche humana, leche materna donada, leche humana, COVID-19, pandemia y Sars-CoV-2 en portugués e inglés. Resultados y discusión: Como el virus COVID-19 se transmite por gotitas respiratorias y el virus sobrevive por períodos variables en superficies inanimadas, en este trabajo, observamos las principales medidas de control de la transmisión del virus por la leche materna donada durante todo el proceso de recolección, procesamiento y distribución de leche humana a los recién nacidos en la unidad de cuidado intensivo neonatal. Es necesario un control de calidad con alto rigor higiénico y sanitario de la leche materna donada, como la esterilización de materiales que entran en contacto con la leche materna, limpieza del ambiente donde se realizará el ordeño, uso de gorro y máscara, lavado de manos con agua y jabón y eliminación de los primeros chorros de leche ordeñada. Conclusión: Las donantes de leche materna ordeñada deben realizar una selección para evaluación y recibir recomendaciones antes de iniciar la donación de leche materna, a fin de evitar la transmisión del virus COVID-19 durante todo el proceso de recolección, procesamiento y distribución del leche materna a los recién nacidos en la unidad de cuidado intensivo neonatal.

Palabras clave: Lactancia materna; Leche humana; Bancos de leche humana; COVID-19; Recién nacidos.

\section{Introdução}

O leite materno é reconhecido e recomendado como fonte nutricional e imunológica ideal para saúde infantil (Daniels et al., 2017; Dawod \& Marshall, 2019). No entanto, algumas condições podem levar a dificuldades no estabelecimento e manutenção do aleitamento materno (Picaud \& Buffin, 2017). Na impossibilidade do aleitamento materno, a Organização Mundial da Saúde (OMS) e a Fundo das Nações Unidas para Infância (UNICEF) recomendam o leite humano doado como a melhor alternativa de terapia nutricional para bebês com baixo peso ao nascer internados em Unidade de Terapia Intensiva 
Neonatal (UTIN) (Fang et al., 2021). Os Bancos de Leite Humano (BLH) são serviços especializados responsáveis pelas atividades de coleta, processamento, controle de qualidade, armazenamento e transporte do leite humano doado (LHD) até o destinatário final (Kim et al., 2010).

Os BLH têm se mostrado como um dos mais importantes elementos estratégicos da política pública em favor da amamentação, realizando a coleta, processamento e distribuição do leite humano doado a recém-nascidos (RN) prematuros e de baixo peso (Landers \& Updegrove, 2010). Porém, frente a nova pandemia da doença do novo Coronavirus Sars-CoV-2 (COVID-19) (Moro \& Bertino, 2020), a demanda de leite humano doado para recém-nascidos de alto risco internados em UTIN é cada vez maior (Salvatori et al., 2021).

A pandemia do COVID-19 é caracterizada como uma emergência cuja magnitude não é encontrada há um século. A Organização Mundial da Saúde (OMS) decretou a disseminação do COVID-19 como pandemia em 11 de março de 2020. O estado de emergência decretado se deve pela alta morbidade e mortalidade generalizada associada ao COVID-19, o que reflete diretamente no impacto econômico e social dos países (Salvatori et al., 2021). As emergências são reconhecidas pelo UNICEF e pela OMS como "Estratégia Global para a Alimentação de Lactentes e Crianças de Primeira Infância", uma das circunstâncias excepcionalmente difíceis, onde à atenção especial deve ser dada ao apoio, incentivo e promoção ao aleitamento materno. Entretanto, infelizmente, a promoção e incentivo à amamentação estão contidos nas políticas e orientações desenvolvidas em resposta à pandemia (Gribble et al., 2020).

Os reflexos da pandemia do COVID-19 estão afetando o mundo e toda a atividade médica, incluindo o funcionamento dos BLH e as doações de leite humano. As pessoas adquiriram o hábito de não saírem de casa, ou saírem apenas para demandas extraordinárias e de não receber visitas ou pessoas em suas próprias casas, o que resulta em menor doação de leite materno para os BLH. Estes novos hábitos estão diretamente relacionados à menor doação de leite humano doado aos BLH, porém, a demanda de leite materno doado para os BLH continua alta. Isso reflete em menor pasteurização de leite humano doado pelos BLH e, consequentemente, menor fornecimento aos recém-nascidos hospitalizados, e ainda na impossibilidade de fornecer leite materno doado para bebês em atendimento ambulatorial e/ou domiciliar (Marinelli, 2020). Desta forma, o objetivo do nosso trabalho foi discutir as recomendações de doação de leite materno a Bancos de Leite Humano frente à pandemia do COVID-19.

\section{Metodologia}

O presente estudo é uma revisão narrativa e descritiva sobre evidências científicas referentes às recomendações de doação de leite materno aos Bancos de Leite Humano frente à pandemia do COVID-19. A pesquisa foi realizada envolvendo publicações sobre Banco de Leite Humano, leite humano doado e COVID-19 indexados nas bases de dados eletrônicas PubMed (US National Library of Medicine), Scientific Electronic Library Online Brasil (SciELO), Web of Science e Portal Capes. Os descritores que delimitaram a pesquisa foram: amamentação, aleitamento materno, banco de leite humano, leite humano doado, leite humano, COVID-19, pandemia e Sars-CoV-2 em português e inglês. Os artigos selecionados foram obtidos e revisados buscando informações relacionadas às recomendações de doação de leite materno a Bancos de Leite Humano frente à pandemia do COVID-19. Todo o processo envolveu atividades de busca, leitura exploratória e resumos, seleção dos estudos considerados adequados aos objetivos deste estudo, análise completa dos textos e, por fim, à realização de leitura e escrita interpretativas.

\section{Resultados e Discussão}

\subsection{Bancos de leite Humano}

Apesar da recomendação e importância do aleitamento materno exclusivo (AME), algumas condições podem levar à 
dificuldades no estabelecimento e manutenção do AME, como a prematuridade, hospitalização neonatal, doenças maternas, óbito materno ou baixa produção de leite (de Halleux et al., 2017). Portanto, o uso do leite humano doado tornou-se uma alternativa eficiente para o aleitamento materno. Nesse sentido, os BLH são serviços especializados, responsáveis por ações de promoção, proteção e apoio do aleitamento materno, bem como, pelo desempenho das atividades de coleta, processamento, controle de qualidade e distribuição do leite humano doado até o receptor final (Borges et al., 2018; Meneses et al., 2017), como é demonstrado na Figura 1.

Figura 1. Fluxograma de rotina de armazenamento e transporte do leite humano doado para os Bancos de Leite Humano até o receptor final em Unidade de Terapia Intensiva Neonatal.

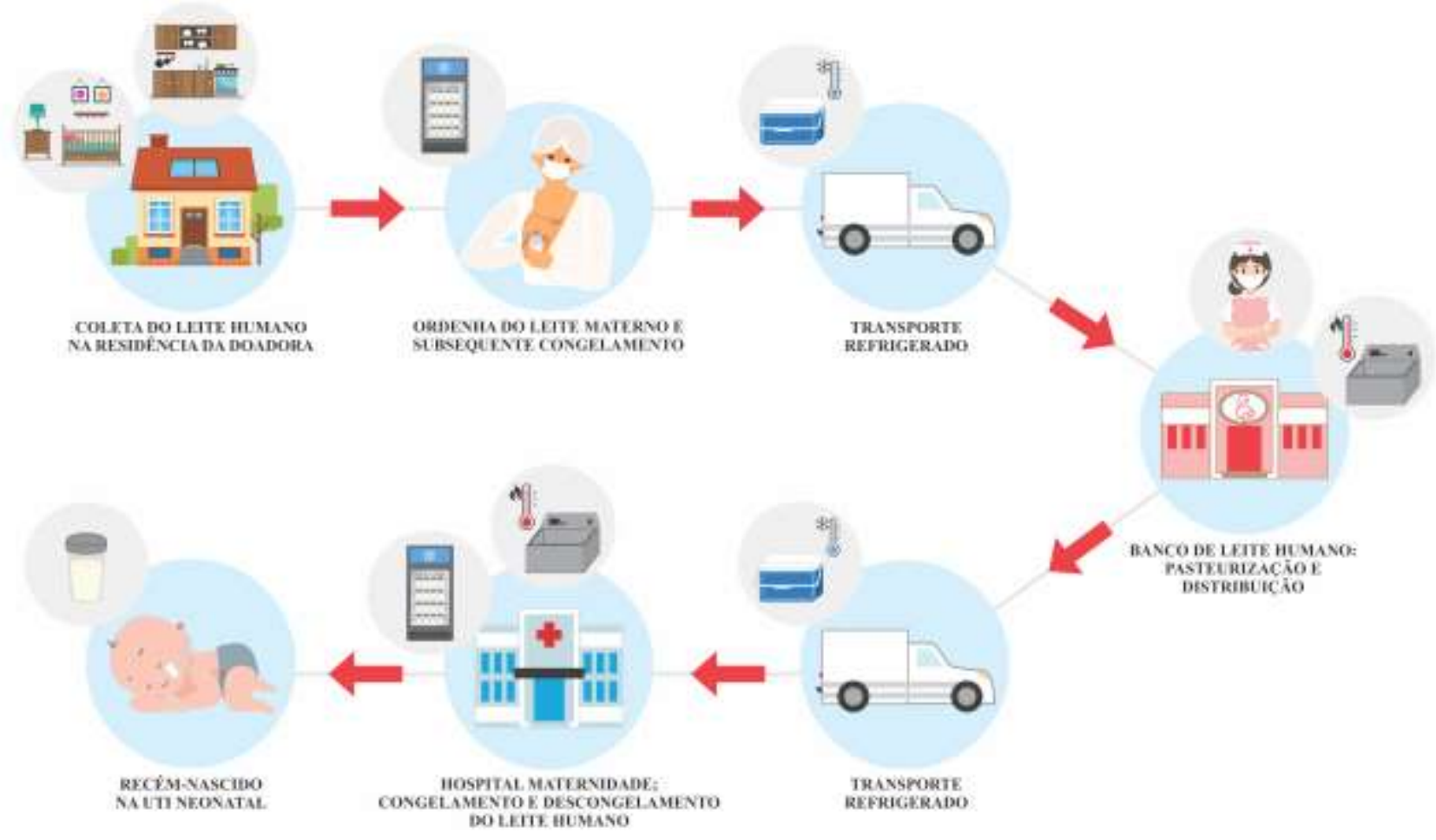

Fonte: Autores.

Nos BLH no Brasil, o leite humano ordenhado ou pasteurizado deve ser obrigatoriamente transportado sob cadeia fria, que se caracteriza pela condição na qual os produtos refrigerados e congelados devem ser mantidos, sob controle e registro, desde a coleta até o consumo, com o objetivo de impedir o crescimento da microbiota capaz de promover alterações em sua composição. As temperaturas limítrofes para transporte são: i) produtos refrigerados: máxima de $5^{\circ} \mathrm{C}$; ii) produtos congelados: $-3^{\circ} \mathrm{C}$ ou inferior. Para garantir as temperaturas limítrofes descritas, é obrigatória a utilização de gelo reciclável na proporção de 3 litros para cada litro de leite tanto para leite humano cru, que é o que vem da casa da doadora para o BLH como do leite humano pasteurizado que é o que vai do BLH para hospitais, postos de coleta e domić́lio para ser consumido de acordo com a RDC n ${ }^{\circ}$ 171/2006 (Brasil, 2006). Para assegurar a manutenção da cadeia a frio no decorrer do transporte, a legislação preconiza que o tempo entre o recebimento do produto na casa da doadora e a entrega na recepção do Banco de Leite não deverá ultrapassar 6 horas. Os produtos liofilizados poderão ser transportados à temperatura ambiente segundo a RDC $\mathrm{n}^{\circ}$ 171/2006 (Brasil, 2006).

O leite humano ordenhado destinado ao consumo do recém-nascido, particularmente os internados em UTIN, não 
deve apresentar microrganismos em quantidade ou qualidade capazes de representar agravos à saúde. Desta forma, é preciso que se disponha de procedimentos capazes de assegurar a qualidade sanitária do leite humano ordenhado. A legislação brasileira RDC $n^{\circ}$ 171/2006 (Brasil, 2006) preconiza que o leite humano necessita receber tratamento térmico para que haja inativação dos possíveis microrganismos patogênicos.

O modelo brasileiro de BLH é reconhecido mundialmente pelo desenvolvimento tecnológico inédito, que alia baixo custo à alta qualidade, além de distribuir o leite humano conforme as necessidades específicas de cada $\mathrm{RN}$, aumentando a eficácia da iniciativa para a redução da mortalidade neonatal (Fang et al., 2021; Marinelli, 2020).

A pasteurização representa uma alternativa eficaz, trata-se de um tratamento térmico aplicável ao leite humano que adota como referência a inativação térmica do microrganismo mais termorresistente, a Coxiella burnetti. Uma vez observado o binômio temperatura de inativação e tempo de exposição capaz de inativar esse microrganismo, pode-se assegurar que os demais patógenos também estarão termicamente inativados. A pasteurização, conduzida a 62,5oC por 30 minutos, não visa a esterilização do leite humano ordenhado, mas sim a inativação de 100\% dos microrganismos patogênicos presentes, quer por contaminação primária ou secundária, além de 99,99\% da microbiota saprófita. Os BLH são conhecidos por ter compromisso entre a segurança microbiológica e a qualidade dos compostos nutricionais e bioativos do leite humano doado (Boyd et al., 2007).

\subsection{Banco de Leite Humano frente à pandemia COVID-19}

A Síndrome Respiratória Aguda Grave Coronavírus-2 (SARS-CoV-2) é altamente contagiosa e foi identificada pela primeira vez na China, em dezembro de 2019. O risco de transmissão através do leite materno e o impacto da infecção por COVID-19 em neonatos em aleitamento materno precisam ser cuidadosamente equilibrados com as consequências negativas para a saúde a curto e longo prazo de não amamentar os recém-nascidos (Peng et al., 2020).

A capacidade de fornecer leite humano doado a todos os recém-nascidos internados em UTIN contribuiu para que o sistema de saúde atinja os compromissos de saúde, aos direitos humanos de acesso a alimentação e aos objetivos de desenvolvimento sustentável propostos pela Organização das Nações Unidas (ONU) referente à nutrição materno-infantil. Ao mesmo tempo questões técnicas e orientações a doadoras de leite humano precisam ser esclarecidas com urgência para minimizar o potencial dano dos reflexos da pandemia do COVID-19 frente à doação de leite materno aos BLH (Fang et al., 2021).

A pandemia afetou a demanda de leite humano nos BLH, como observado na China (Marinelli, 2020), um dos motivos seria o receio das mães em sair de casa, além disso, outra causa possível é que as doadoras precisam passar por uma triagem e seleção, e ainda, com o emocional afetado, a produção de leite pelas glândulas mamárias das mães diminui. A triagem da coleta do leite humano pelos BLH tornou-se mais cuidadosa e rigorosa com o novo vírus. Na China, antes do surto, as doadoras podiam coletar o leite humano em suas casas e entregá-los aos BLH; agora, todo leite humano coletado é realizado pessoalmente, nos BLHs, em que é averiguada a temperatura da doadora, e ainda, ela é obrigada a preencher um questionário, com perguntas sobre ela, desde o estado de saúde até se esteve em viagem recentemente.

Segundo a associação de banco de leite europeia (European Milk Bank Association, 2020), na Europa, o volume de leite humano doado também reduziu significativamente, as mães preferem ficar mais longe possível dos hospitais; e ainda, mesmo que a coleta do leite humano estiver sendo realizada em casa, essa atividade foi reduzida, pelo fato de que todos os esforços dos hospitais são dedicados às pessoas infectadas com COVID-19 (Moro \& Bertino, 2020).

\subsection{Recomendações de boas práticas na coleta de leite humano doado para Bancos de Leite humano}

Como o vírus da COVID-19 é transmitido por gotículas respiratórias e os vírus sobrevivem por períodos variados em superfícies inanimadas, na Figura 2 observamos as principais medidas para garantir o controle de qualidade do leite humano 
doado evitando à transmissão do vírus durante todo o processo de coleta, processamento e distribuição do leite humano doado até os recém-nascidos das UTIN (Marinelli \& Lawrence, 2020).

Figura 2. Fluxograma de medidas de controle de qualidade da amamentação e do leite humano doado para os Bancos de Leite Humano.

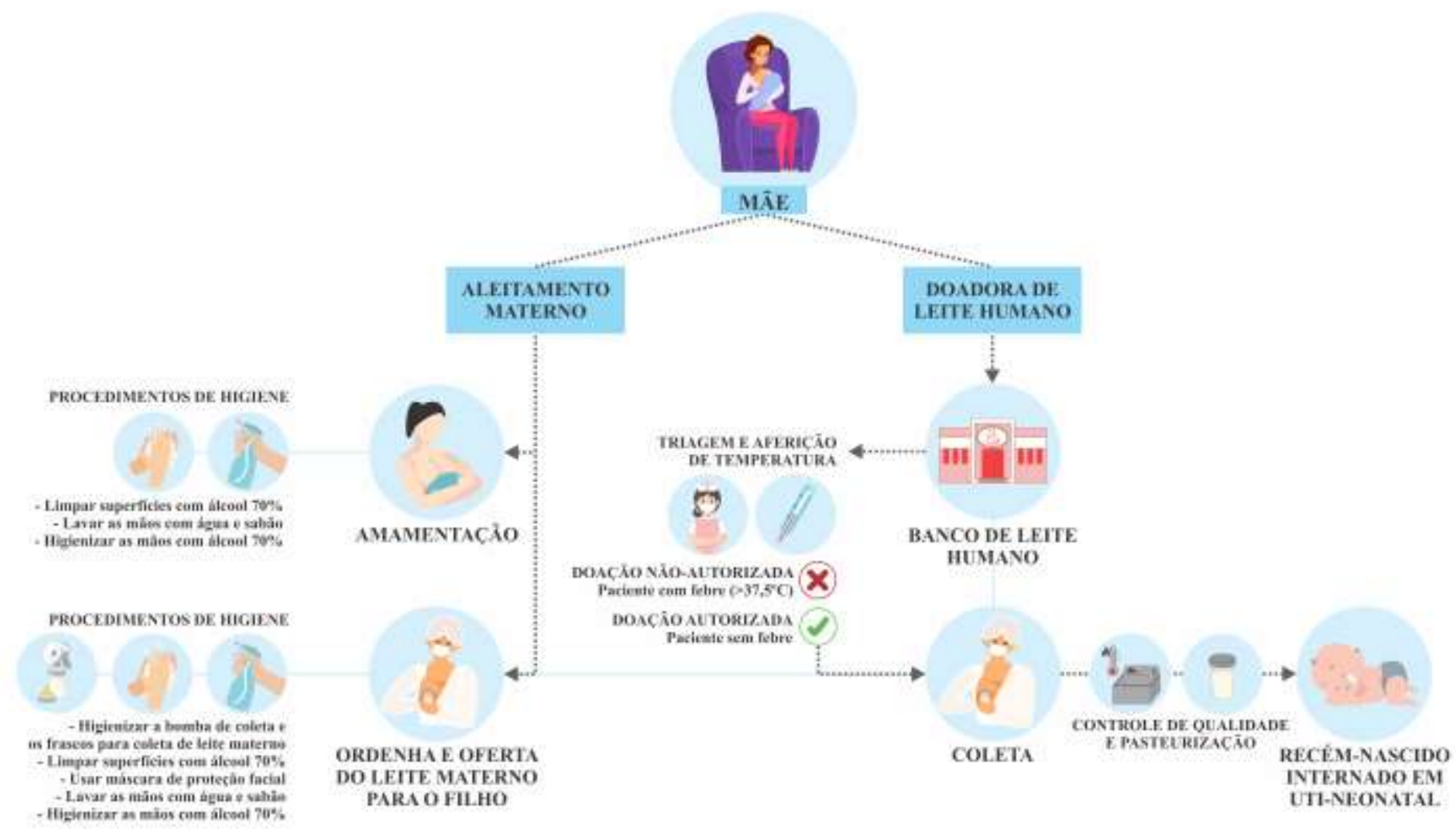

Fonte: Autores.

As mães que amamentam e que são doadoras de leite humano devem seguir as precauções necessárias para a proteção e controle de infecções, usando máscaras respiratórias e empregando boas práticas de lavagem das mãos antes e depois da coleta. Devem realizar a desinfecção do local de ordenha e assim como dos recipientes utilizados para o armazenamento do leite humano ordenhado, a fim de garantir a segurança dos recém-nascidos que são amamentados ou que recebem o leite humano doado dos BLH contra a propagação ou contaminação pelo vírus. Essas medidas devem se estender para os hospitais com UTIN, BLH e unidades de coleta de leite humano doado para que adotem medidas de proteção e contenção da COVID-19 ao longo desta pandemia, ou até que haja evidências de segurança nesse processo (Marinelli \& Lawrence, 2020).

A infecção humana causada pelo SARS-CoV-2 é uma emergência de saúde pública de importância internacional. Por estar passando por uma fase de transmissão comunitária em muitos locais do mundo, torna-se necessária a orientação aos serviços de saúde que realizam a coleta, armazenamento e processamento de leite humano. No Brasil, é de responsabilidade dos BLH e dos postos de coleta de leite humano a recomendação de que somente lactentes saudáveis e sem contato domiciliar com pessoas que apresentem síndrome gripal ou caso confirmado de COVID-19 possam doar leite, bem como, de seguir os protocolos do Ministério da Saúde para avaliação sobre risco de síndrome gripal e as normas técnicas disponíveis, visto que estas, se seguidas no momento da ordenha, coleta, processamento e controle de qualidade, são suficientes para garantir a segurança biológica dos profissionais e produto, não sendo necessárias, etapas posteriores de processamentos (Ministério da 
Saúde, 2020).

Nos BLHs brasileiros, para que seja mantida a qualidade na ordenha, esta deve ser conduzida com rigor higiênicosanitário, sendo necessárias medidas como: esterilização dos materiais que entrarem em contato com o leite; não utilização de acessórios pessoais e produtos que exalem cheiro; obrigatoriedade de utilização de gorro e máscara; lavagem das mãos com água e sabão; eliminação dos primeiros jatos de leite, visto que representam fator de risco para a ocorrência de não conformidades em leite humano ordenhado (Almeida et al., 2005).

Já no processamento, a etapa de pasteurização, que ocorre à temperatura de $62,5^{\circ} \mathrm{C}$ por 30 minutos, não visa a esterilização do leite humano ordenhado, mas assegura a inativação de $100 \%$ dos microrganismos patogênicos que possam estar presentes, além de 99,99\% da microbiota saprófita ou normal (Almeida et al., 2005). De acordo com Chen et al. (2020), embora as propriedades do SARS-CoV-2 não tenham sido definidas claramente, supõe-se que este seja sensível à radiação ultravioleta e ao aquecimento, visto que, de acordo com pesquisas realizadas com SARS-CoV e MERS-COV, o vírus pode ser inativado por aquecimento a $56^{\circ} \mathrm{C}$ por 30 minutos ou usando determinados solventes lipídicos.

A Organização Mundial da Saúde (World Health Organization, 2020) elaborou orientações sobre como prevenir e controlar as infecções na amamentação em tempos de COVID-19. Eles afirmam que os bebês nascidos de mães suspeitas do novo vírus, devem ser alimentados conforme as diretrizes de alimentação infantil, porém utilizando as precauções necessárias para essa proteção. Essa recomendação consiste em que todas as crianças deverem iniciar a amamentação dentro da primeira hora após o nascimento. Além disso, mães sintomáticas que estejam amamentando e mantendo contato com o neonato, devem realizar a higiene das mãos antes e após o contato com o RN, além de efetuar a higiene respiratória com o uso de máscara de proteção facial e a limpeza e desinfecção das superfícies com as quais a mãe esteve em contato.

Com a pandemia, não é possível ter certeza de quem está infectado se não tiver sido testado, e como esse vírus é transmitido por gotículas respiratórias que sobrevivem por vários períodos em superfícies inanimadas, cabe aos bancos de leite humano orientar as doadoras no sentido de garantir que não transmitam o vírus para o leite humano doado, para alimentar o próprio bebê ou para doar para o BLH. Para isso, todas as mães devem seguir as recomendações da Organização Mundial da Saúde (World Health Organization, 2020), com o uso de máscaras respiratórias, higienização das mãos, antes e após a coleta do leite humano e/ou o contato com o bebê, e limpeza e desinfecção do local (Marinelli, 2020).

O leite humano coletado pelas mães para a doação deve estar em recipientes limpos. Após cada sessão de coleta, todas as partes da bomba de sucção que entram em contato com o leite humano devem ser lavadas e desinfetadas, de acordo com as instruções do fabricante (CDC, 2020).

Além desses cuidados pessoais e em relação ao ambiente de coleta do LH pelas mães, sugere-se que os recipientes sejam recebidos pelas próprias mães, ou ao abrir as caixas térmicas com o leite humano doado por outras pessoas, que seja realizado usando luvas, e depois higienizado a superfície externa destes recipientes (Marinelli, 2020).

Como já mencionado anteriormente, o SARS-CoV-2 é um vírus transmitido por gotículas respiratórias, a orientação é que seja realizado o uso de jalecos, luvas, máscara respiratória e proteção de olhos, sempre que houver o contato com recémnascidos de mães com suspeita ou confirmação de COVID-19. A separação temporária entre o recém-nascido e a mãe pode minimizar o risco de infecção do bebê pelas secreções respiratórias maternas, sendo que, após a higiene adequada das mamas e mãos, o leite coletado pela mãe pode ser oferecido ao neonato por cuidadores. Caso a mãe opte por permanecer com o bebê, estes devem manter uma distância de seis pés ou dois metros, ou uma barreira física deve ser usada, como uma cortina (Gribble et al., 2020)

Ainda, como as grávidas possuem alterações fisiológicas no sistema imunológico, elas são mais suscetíveis à infecção deste vírus. Assim, para evitar o contágio, é recomendado que elas evitem multidões, transportes públicos, contato com pessoas doentes e que pratiquem uma boa higiene pessoal e social. Caso apresentarem sintomas como febre, fadiga, mialgia, 
dor de garganta ou falta de ar, devem procurar atendimento médico. E em relação aos cuidados do recém-nascido em época de COVID-19, os dados sugerem que não é possível uma transmissão transplacentária no final da gravidez próximo do nascimento da criança, pois o vírus não foi identificado no líquido amniótico, na placenta, no leite humano de mães infectadas, e nem nas secreções nasais dos RN (Liang \& Acharya, 2020).

\section{Conclusão}

As doadoras de leite humano ordenhado devem realizar uma triagem nos BLH para avaliação e recomendações antes de iniciar a doação de leite humano, a fim de evitar a transmissão do vírus da COVID-19 durante todo o processo de coleta, processamento e distribuição do leite humano até os recém-nascidos das UTIN. Entretanto, doadoras sintomáticas ou com diagnóstico de infecção pelo vírus da COVID-19 não devem doar o leite humano ordenhado para os Bancos de Leite Humano. Doadoras saudáveis e assintomáticas devem seguir todo o padrão de controle de qualidade na ordenha, armazenamento e transporte do leite humano ordenhado para evitar contaminações.

Neste momento, o incentivo do aleitamento materno pelos profissionais de saúde e campanhas de doação de leite humano ordenhado para os Bancos de Leite Humano no Brasil são importantes, uma vez que estes índices se apresentavam significativamente baixos antes da pandemia no Brasil, e podem se tornar ainda piores após a pandemia.

\section{Agradecimentos}

Ao Conselho Nacional de Desenvolvimento Científico e Tecnológico (CNPq), à Coordenação de Aperfeiçoamento de Pessoal de Nível Superior (CAPES), à Fundação Araucária de Apoio ao Desenvolvimento Científico e Tecnológico do Estado do Paraná (FAPPR) e à Universidade Estadual de Maringá.

\section{Referências}

Almeida, J., Guimarães, V., \& Novak, F. (2005). Normas técnicas Redeblh-Br para bancos de leite humano: Seleção e classificação. Rio de Janeiro: Fiocruz/IFF-BLH.

Borges, M. S., Oliveira, A. M. de M., Hattori, W. T., \& Abdallah, V. O. S. (2018). Quality of human milk expressed in a human milk bank and at home. Jornal de Pediatria, 94(4), 399-403. https://doi.org/10.1016/j.jped.2017.07.004

Boyd, C. A., Quigley, M. A., \& Brocklehurst, P. (2007). Donor breast milk versus infant formula for preterm infants: Systematic review and meta-analysis. Archives of Disease in Childhood - Fetal and Neonatal Edition, 92(3), F169-F175. https://doi.org/10.1136/adc.2005.089490

Brasil (2006). Agência Nacional de Vigilância Sanitária (ANVISA). Resolução da Diretoria Colegiada da ANVISA - RDC nº 171 de 04 setembro de 2006. Dispõe sobre o regulamento, a implantação e o funcionamento de Bancos de Leite Humano no território nacional. Diário Oficial da União. Brasília, DF: Ministério da Saúde; Seção 1. p. 33.

Chen, Z.-M., Fu, J.-F., Shu, Q., Chen, Y.-H., Hua, C.-Z., Li, F.-B., Lin, R., Tang, L.-F., Wang, T.-L., Wang, W., Wang, Y.-S., Xu, W.-Z., Yang, Z.-H., Ye, S., Yuan, T.-M., Zhang, C.-M., \& Zhang, Y.-Y. (2020). Diagnosis and treatment recommendations for pediatric respiratory infection caused by the 2019 novel coronavirus. World Journal of Pediatrics, 16(3), 240-246. https://doi.org/10.1007/s12519-020-00345-5

Control, C. for D., Prevention, \& others. (2020). Interim considerations for infection prevention and control of coronavirus Disease 2019 (COVID-19) in inpatient obstetric healthcare settings. Acessado em, 18(02).

Daniels, B., Schmidt, S., King, T., Israel-Ballard, K., Amundson Mansen, K., \& Coutsoudis, A. (2017). The Effect of Simulated Flash-Heat Pasteurization on Immune Components of Human Milk. Nutrients, 9(2), 178. https://doi.org/10.3390/nu9020178

Dawod, B., \& Marshall, J. S. (2019). Cytokines and Soluble Receptors in Breast Milk as Enhancers of Oral Tolerance Development. Frontiers in Immunology, 10, 16. https://doi.org/10.3389/fimmu.2019.00016

de Halleux, V., Pieltain, C., Senterre, T., \& Rigo, J. (2017). Use of donor milk in the neonatal intensive care unit. Seminars in Fetal and Neonatal Medicine, 22(1), 23-29. https://doi.org/10.1016/j.siny.2016.08.003

European Milk Bank Association. (2020). COVID-19: EMBA position statement. https://europeanmilkbanking.com/covid-19-emba-position-statement/

Fang, M. T., Grummer-Strawn, L., Maryuningsih, Y., \& Biller-Andorno, N. (2021). Human milk banks: A need for further evidence and guidance. The Lancet Global Health, 9(2), e104-e105. https://doi.org/10.1016/S2214-109X(20)30468-X 
Research, Society and Development, v. 10, n. 8, e30210817258, 2021

(CC BY 4.0) | ISSN 2525-3409 | DOI: http://dx.doi.org/10.33448/rsd-v10i8.17258

Gribble, K., Marinelli, K. A., Tomori, C., \& Gross, M. S. (2020). Implications of the COVID-19 Pandemic Response for Breastfeeding, Maternal Caregiving Capacity and Infant Mental Health. Journal of Human Lactation, 36(4), 591-603. https://doi.org/10.1177/0890334420949514

Kim, J., Unger, S., Canadian Paediatric Society, \& Nutrition and Gastroenterology Committee. (2010). Human milk banking. Paediatrics \& Child Health, 15(9), 595-598. https://doi.org/10.1093/pch/15.9.595

Landers, S., \& Updegrove, K. (2010). Bacteriological Screening of Donor Human Milk Before and After Holder Pasteurization. Breastfeeding Medicine, 5(3), 117-121. https://doi.org/10.1089/bfm.2009.0032

Liang, H., \& Acharya, G. (2020). Novel corona virus disease (COVID-19) in pregnancy: What clinical recommendations to follow? Acta Obstetricia et Gynecologica Scandinavica, 99(4), 439-442. https://doi.org/10.1111/aogs.13836

Marinelli, K. A. (2020). International Perspectives Concerning Donor Milk Banking During the SARS-CoV-2 (COVID-19) Pandemic. Journal of Human Lactation, 36(3), 492-497. https://doi.org/10.1177/0890334420917661

Marinelli, K. A., \& Lawrence, R. M. (2020). Safe Handling of Containers of Expressed Human Milk in all Settings During the SARS-CoV-2 (COVID-19) Pandemic. Journal of Human Lactation, 36(3), 498-501. https://doi.org/10.1177/0890334420919083

Meneses, T. M. X. de, Oliveira, M. I. C. de, \& Boccolini, C. S. (2017). Prevalence and factors associated with breast milk donation in banks that receive human milk in primary health care units. Jornal de Pediatria, 93(4), 382-388. https://doi.org/10.1016/j.jped.2016.09.004

Ministério da Saúde (2020) Secretaria de atenção primária à saúde. Nota técnica No 8/2020-COCAM/CGCIVI/DAPES/SAPS/MS p. 1-13. https://saude.es.gov.br/Media/sesa/coronavirus/Notas\%20Técnicas/NOTA\%20TÉCNICA\%20COVID.19\%20N.\%2013.20\%20Organização\%20da\%20Rede\% 20Assistencial\%20Gestante.pdf

Moro, G. E., \& Bertino, E. (2020). Breastfeeding, Human Milk Collection and Containers, and Human Milk Banking: Hot Topics During the COVID-19 Pandemic. Journal of Human Lactation, 36(4), 604-608. https://doi.org/10.1177/0890334420934391

Peng, S., Zhu, H., Yang, L., Cao, L., Huang, X., Dynes, M., Narayan, A., Xia, J., Chen, Y., Zhang, P., Liu, H., Li, H., \& Xia, S. (2020). A study of breastfeeding practices, SARS-CoV-2 and its antibodies in the breast milk of mothers confirmed with COVID-19. The Lancet Regional Health - Western Pacific, 4, 100045. https://doi.org/10.1016/j.lanwpc.2020.100045

Picaud, J.-C., \& Buffin, R. (2017). Human Milk-Treatment and Quality of Banked Human Milk. Clinics in Perinatology, 44(1), 95-119. https://doi.org/10.1016/j.clp.2016.11.003

Salvatori, G., De Rose, D. U., Amadio, P., Reposi, M. P., Piccioni, L., Concato, C., \& Dotta, A. (2021). Universal Screening for SARS-CoV-2 of all Human Milk Bank Samples. Journal of Human Lactation, 37(1), 40-42. https://doi.org/10.1177/0890334420962074

World Health Organization. (2020). Clinical management of severe acute respiratory infection (SARI) when COVID-19 disease is suspected. Interim guidance. Pediatria i Medycyna Rodzinna, 16(1), 9-26. https://doi.org/10.15557/PiMR.2020.0003 